\title{
0 modo de vida do idoso ribeirinho amazônico em imagens e linguajar cultural ${ }^{*}$
}

Rodolfo Gomes do Nascimento(a)

Ronald de Oliveira Cardoso ${ }^{(b)}$ Zeneide Nazaré Lima dos Santos(c)

Denise da Silva Pinto(d) Celina Maria Colino Magalhães(e)

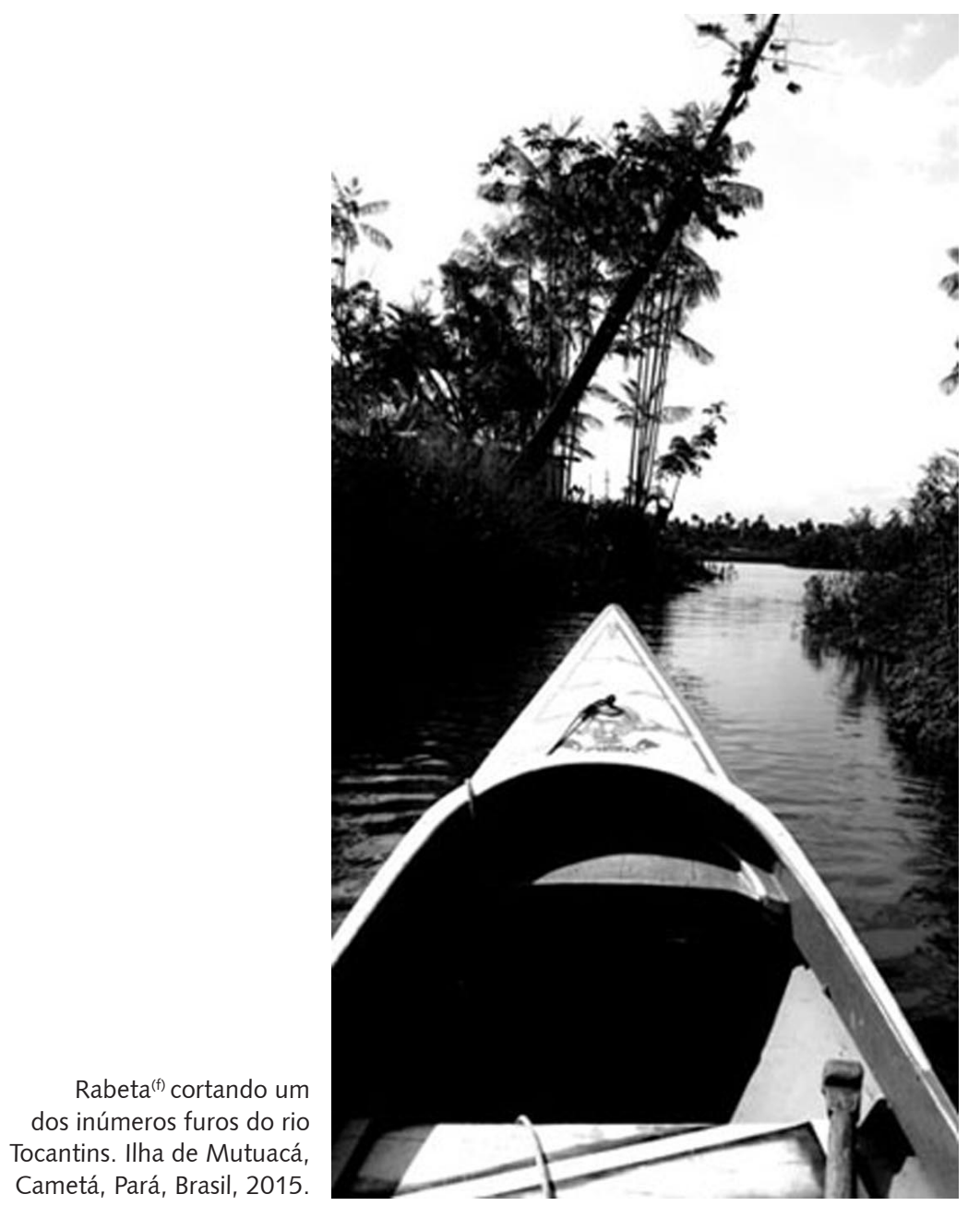

"Financiado pela Capes. Todos os registros fotográficos e textos desta seção são de autoria de Rodolfo Gomes do Nascimento e

Ronald de Oliveira Cardoso.

(a) Doutorando, Programa de

Pós-Graduação em Teoria e

Pesquisa do Comportamento, Universidade Federal do Pará. Rua Augusto Corrêa, 1, Campus Universitário do Guamá. Belém, PA, Brasil. 66075-110. rodgn@hotmail.com

(b) Pós-graduando, Programa de Residência Multiprofissional em Saúde, Saúde da Família, Universidade do Estado do Pará. Belém, PA, Brasil. ronald.cardoso01@hotmail.com

(c) Terapeuta Ocupacional. Belém, PA, Brasil.

zeneidelima_to@yahoo.com.br (d) Curso de Fisioterapia, Faculdade de Fisioterapia e Terapia Ocupacional, Universidade Federal do Pará. Belém, PA, Brasil. denisefisio23@yahoo.com.br

(e) Núcleo de Teoria e Pesquisa do Comportamento, Programa de Pós-Graduação em Teoria e Pesquisa do Comportamento. Belém, PA, Brasil. celinaufpa@gmail.com 


\section{Por onde o rio vergou ${ }^{(g)}$ para conhecer os efeitos do tempo...}

O embarque fascinante nessa produção foi motivado pela pesquisa de doutorado intitulada "Síndrome de Fragilidade em idosos de comunidades ribeirinhas amazônicas", do Núcleo de Teoria e Pesquisa do Comportamento, da Universidade Federal do Pará. Foi uma viagem desafiadora pela realidade cotidiana de um povo que, por vezes, os igarapés, furos e labirintos de rios "escondem". Um oportuno encontro com uma identidade cultural rica, no intuito de revelar o idoso amazônico e seu modo de ser e viver às margens dos rios.

No mês de janeiro e julho de 2015, na intenção de se concretizar a inserção ecológica da pesquisa, percorremos longas estradas e um imenso rio até o município de Cametá, nordeste do estado do Pará, Brasil. A finalidade primordial era visitar algumas das distintas ilhas fluviais do município, e assim fizemos em duas localidades - Carapajó e Juaba. Já embarcados e acompanhando os cursos das "ruas d'água" formadas pelos rios amazônicos, visitamos sete ilhas, sendo elas: Tem-tem, Mutuacá, Mutuacá de Baixo, Mutuacá de Cima, Mutuacazinho, Gama e Mapeuá. Com o pano de fundo que deu forma a essa experiência já posto, finalmente, atracamos nossas "rabetas" de moradia em moradia onde vivem idosos tipicamente ribeirinhos.

\section{A fotografia na nossa ilharga ${ }^{(h)}$ foi ponto de partida e também de chegada}

O embarque fascinante nessa produção foi motivado pela pesquisa de doutorado intitulada "Síndrome de Fragilidade em idosos de comunidades ribeirinhas amazônicas", do Núcleo de Teoria e Pesquisa do Comportamento, da Universidade Federal do Pará. Foi uma viagem desafiadora pela realidade cotidiana de um povo que, por vezes, os igarapés, furos e labirintos de rios "escondem". Um oportuno encontro com uma identidade cultural rica, no intuito de revelar o idoso amazônico e seu modo de ser e viver às margens dos rios.

No mês de janeiro e julho de 2015, na intenção de se concretizar a inserção ecológica da pesquisa, percorremos longas estradas e um imenso rio até o município de Cametá, nordeste do estado do Pará, Brasil. A finalidade primordial era visitar algumas das distintas ilhas fluviais do município, e assim fizemos em duas localidades - Carapajó e Juaba. Já embarcados e acompanhando os cursos das "ruas d'água". 


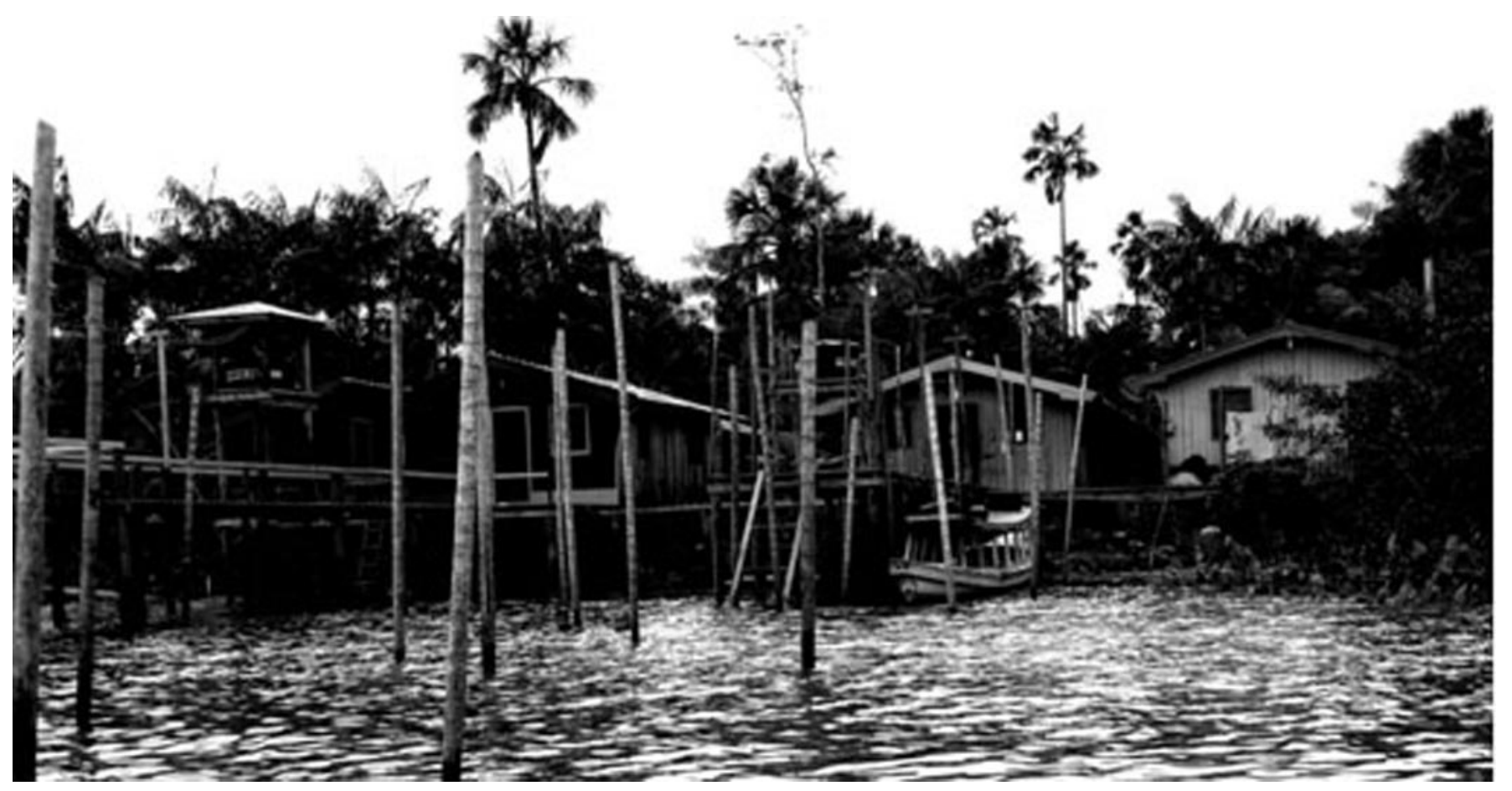

Ambiente ribeirinho, Ilha de Mapeuá. Cametá, Pará, Brasil, 2015.

O caminho que estamos apontando aqui, em grande parte, é pouco conhecido. Sendo assim, nessa experiência, houve uma maior afeição pela composição dos registros fotográficos, que se constituiu como um dos pilares da pesquisa.

Captar o idoso ribeirinho amazônico em sua rotina, o ambiente construído por ele, a paisagem da natureza que o cerca, e, ainda, dialogar com sua percepção em imagens retratadas no cotidiano não foi uma tarefa simples. Desse modo, a fotografia apresentou-se como um inestimável recurso capaz de reproduzir sensivelmente a realidade deparada, subsidiando uma análise mais atenta e densa dos traços culturais "tradicionais" desses idosos. Cabe destacar que, considerando a complexidade do desafio, as intefaces reveladas neste manuscrito não contemplam a totalidade deste rico contexto, no entanto, foram suficientemente capazes de mover um olhar revelador dos costumes amazônicos e das vivências culturais próprias do idoso ribeirinho.

O corpo de imagens obtido durante a pesquisa foi construído pelos próprios pesquisadores. Envolvidos pela curiosidade que ali se despontava, adentraram no cotidiano daquelas pessoas, que, devagar, iam se entregando aos registros. Era assim, espontaneamente, que pretendia-se captar a essência de cada um deles, de cada expressão, de cada trejeito, registrando suas ações e os ambientes onde vivem, de forma plena, sua velhice. Nessa esteira, as ocasiões impuseram duplo desafio para preservar essa naturalização: capturar o realismo no momento oportuno, e, ao mesmo tempo, equilibrar os planos fotográficos em meio às tábuas de madeira, por vezes, das próprias palafitas, por vezes, das embarcações. 
Com base nessa experiência vivenciada e também considerando os diálogos carregados de expressões linguísticas típicas e as representações físicas registradas em fotografias, foram produzidos textos poéticos como forma de representar e dar contextura na realidade retratada.

Os frutos dessa inestimável experiência envolvem, aproximadamente, duzentos e cinquenta fotografias, depoimentos audiogravados e registros científicos que desvendam o cotidiano e caracterizam o ambiente físico e condições de moradia desses povos. A intenção é que, futuramente, também sejam publicizados em revistas científicas.

Por entre braços de rio, furos e igarapés também se envelhece, sumano ${ }^{(i)}$

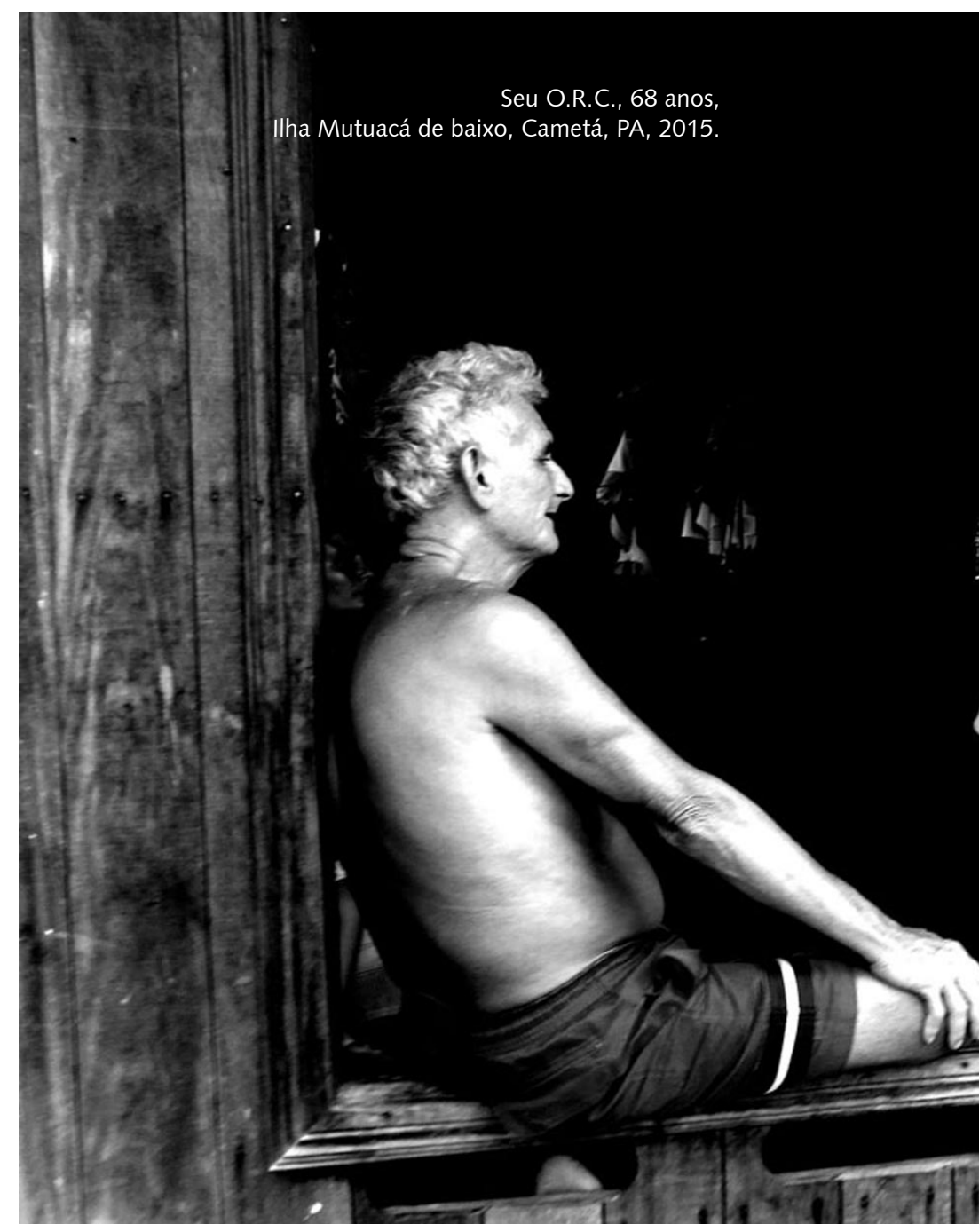


Diante da preocupação escancarada com o fenômeno do envelhecimento no mundo, precisamos conhecer e entender o que nos é peculiar, o que de singular sobrevém por entre nossos rios. É dito, claro e bem documentado, que existem inúmeras formas de se envelhecer, e a cultura é o que impulsiona toda essa diversidade. Bem, cultura, no sentido mais amplo do termo, não nos falta aqui na Amazônia, aliás, é exuberante, "sumano"! Então, o que há de revelar o envelhecer aqui à beirada ${ }^{(j)}$ do rio?

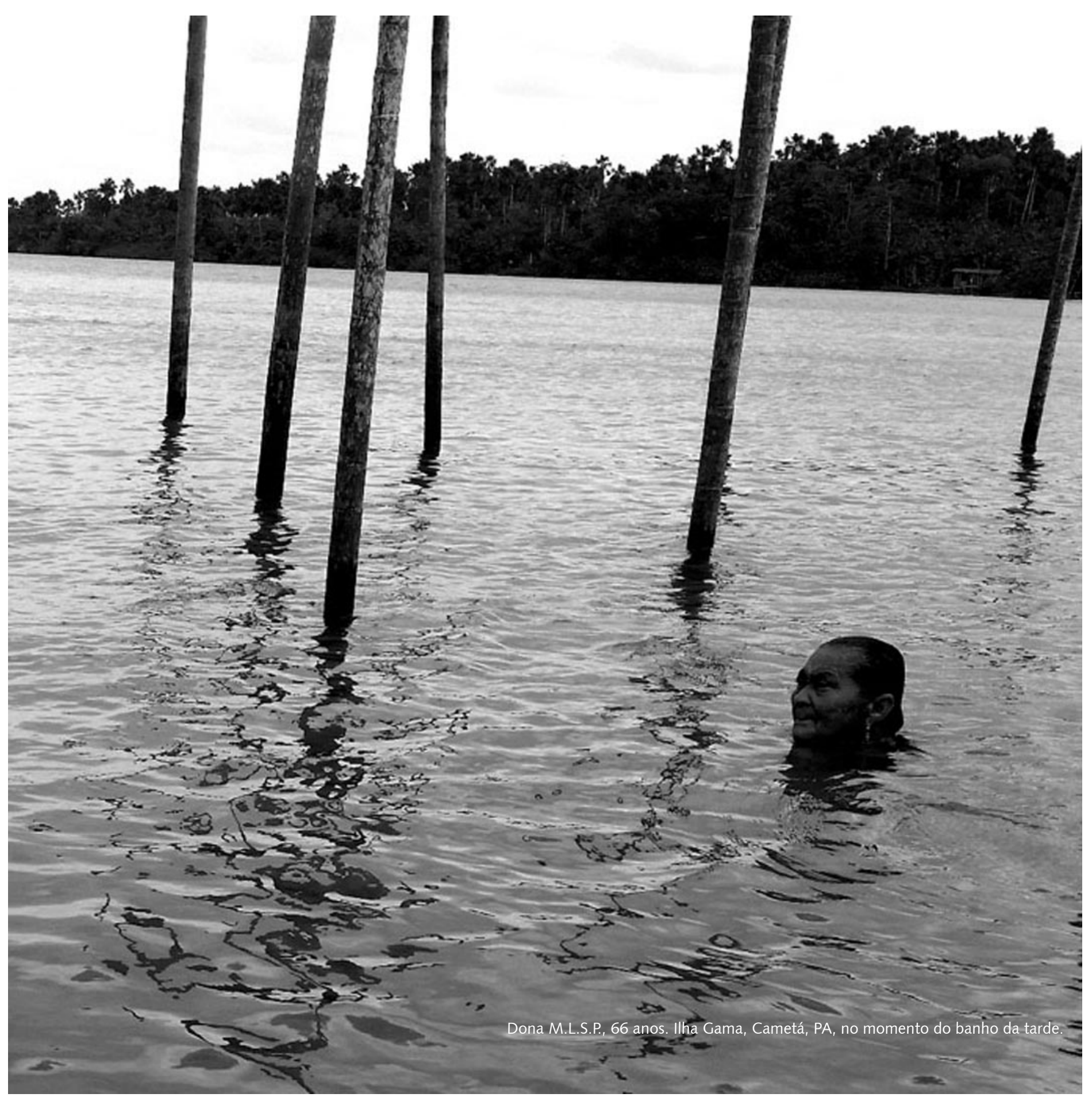




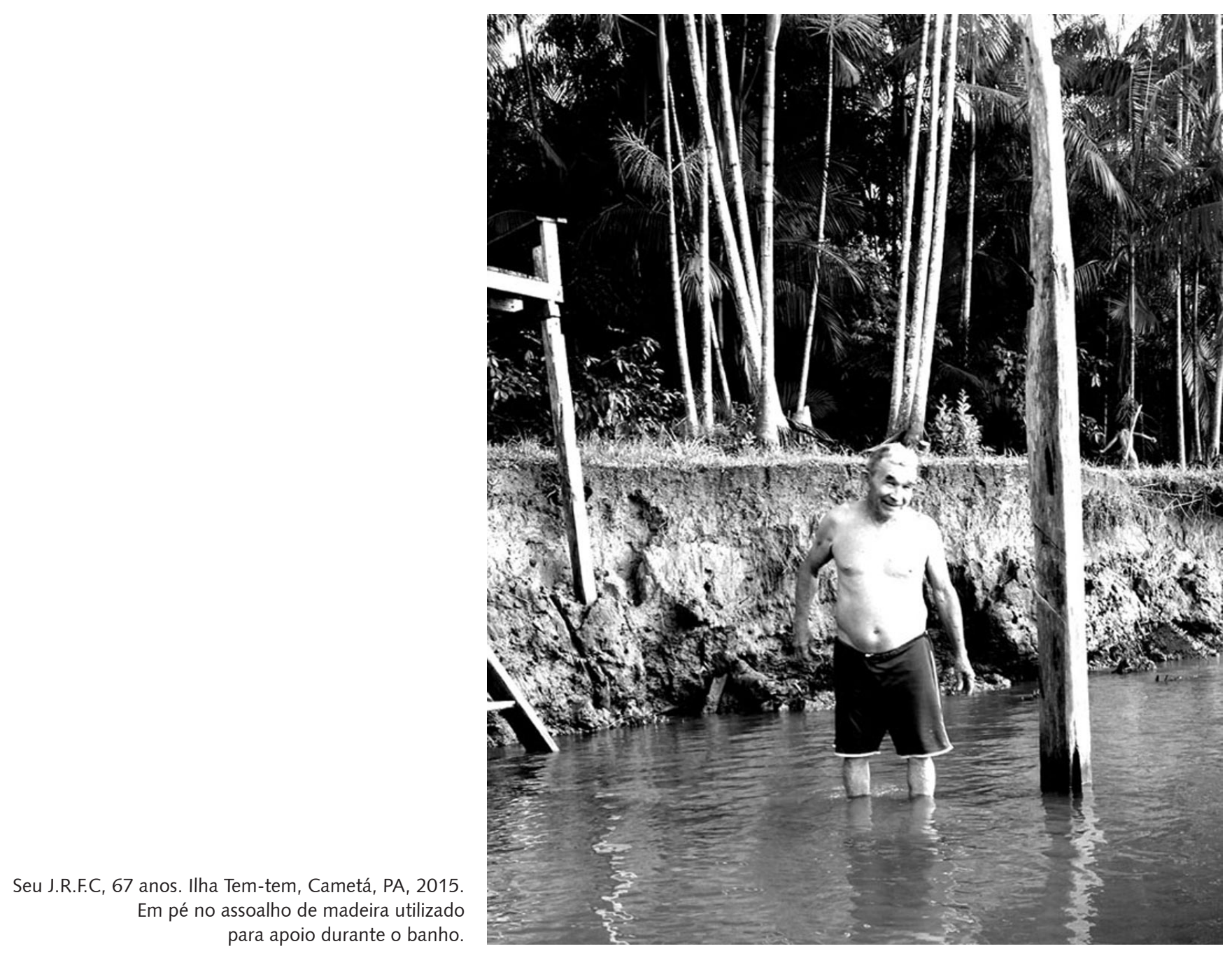

Quando jogo minha rede, esse rio que me alimenta;

$\mathrm{Na}$ enchente ou na vazante sou exímio navegante dessas águas tão barrentas,

Esse rio é minha estrada, meu chão e meu pão. Daqui que tiro meu sustento; Fico só de bubuia(1), deixo passar pelo corpo, arrebatar toda sujeira e até tormento,

De pé nesse assoalho, me equilibro até baixar toda essa quentura; Nada me aperreia o pensamento, nem vazante, nem crescente, muito menos rachadura.

Que orgulho que me dá parente, nem vem que dessas águas não me retiro; Esse rio que escoa e toma a gente, é tão rico e tentador que a ele ofereço até meu último suspiro. 
CRIAÇÃO

“Na época eu 'teve' que trabalhar né, num cheguei a ir muito à escola"

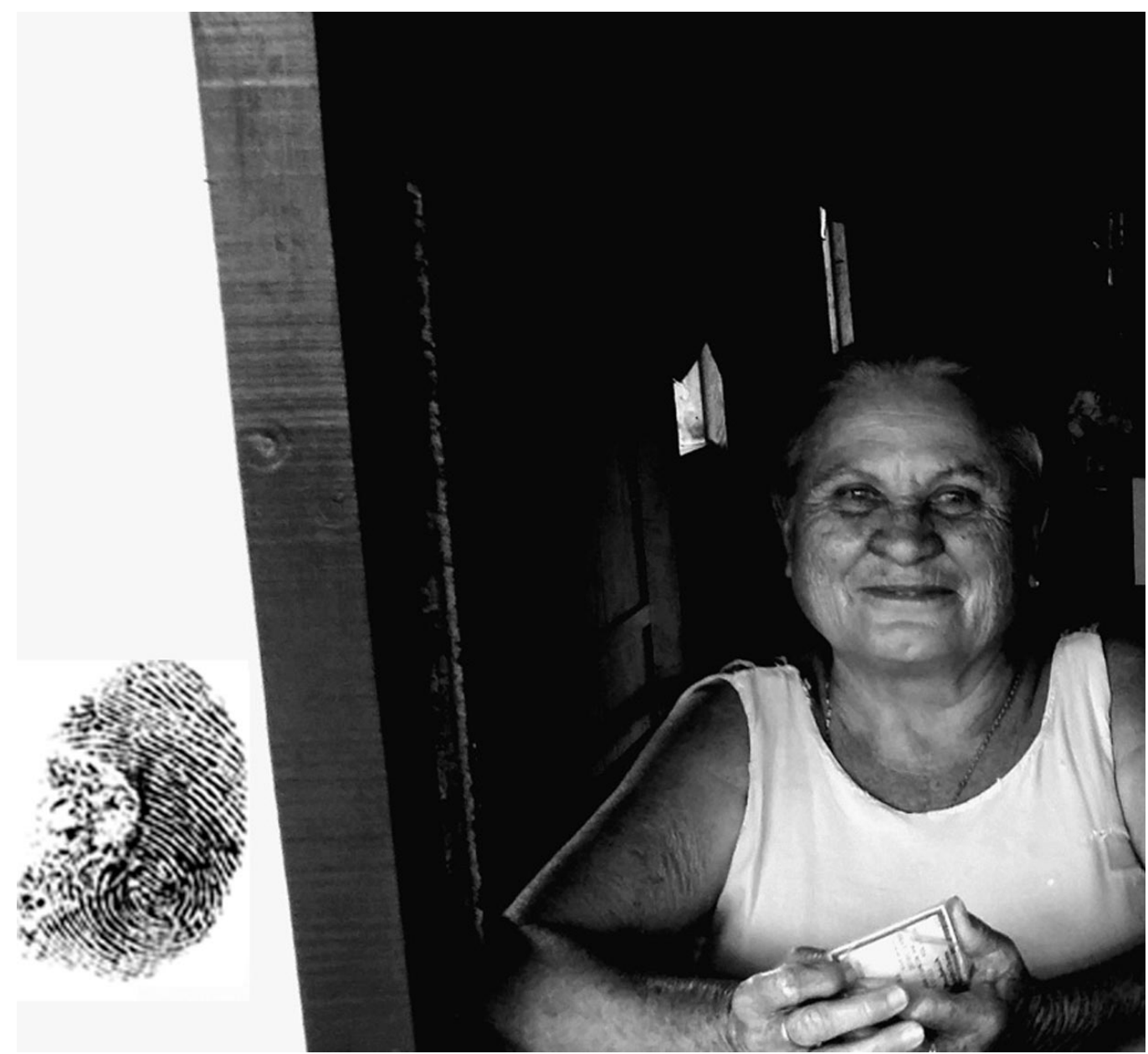

Dona S.R.C., 65 anos. Mutuaca de cima, Cametá, PA, 2015. À esquerda sua impressão digital, a idosa não conseguia assinar seu próprio nome, portanto foi utilizada a assinatura a rogo. 


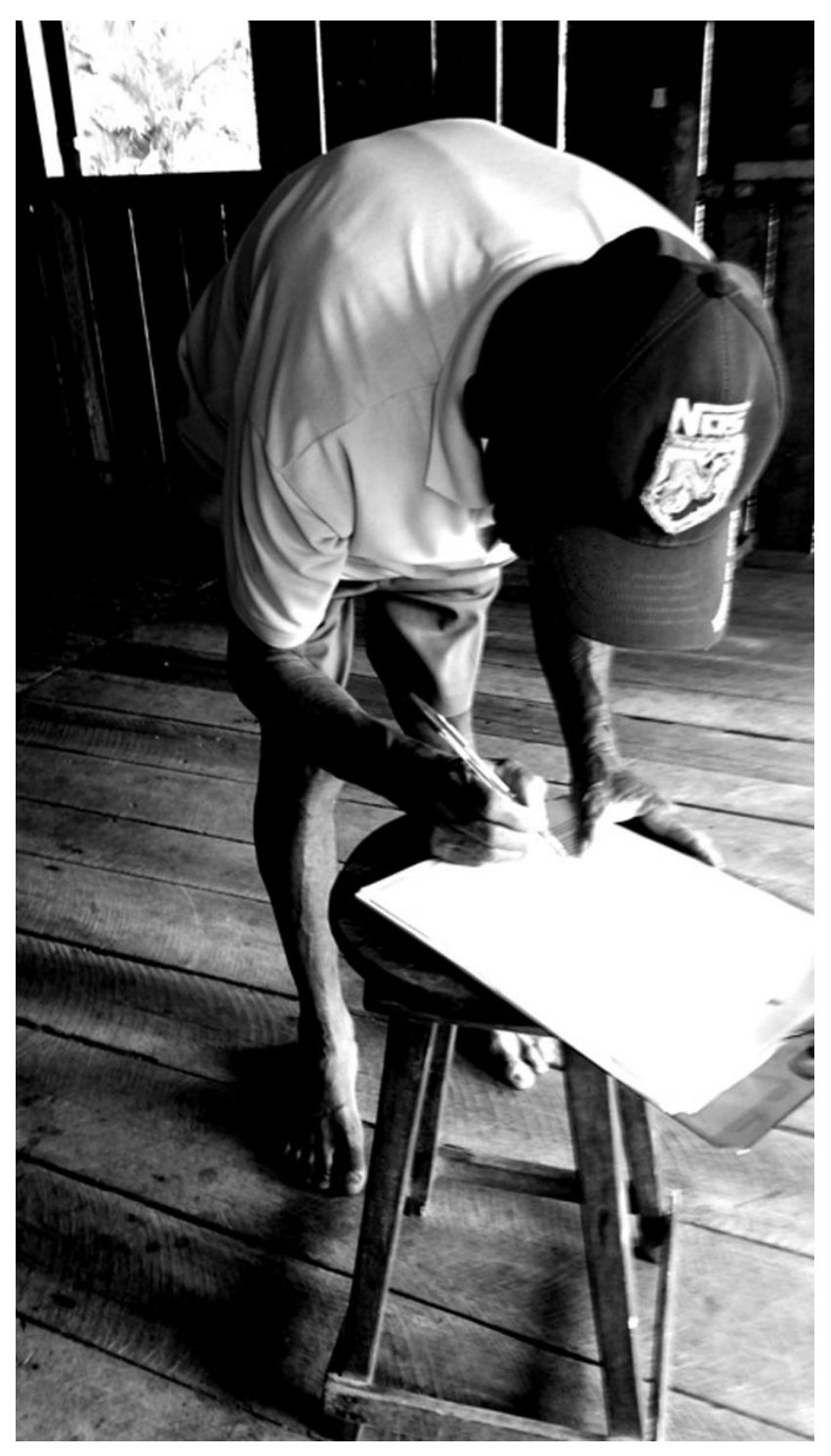

Seu B.M.R, 75 anos. Ilha Mutuacazinho, Cametá, PA, no momento que consentia autorização para participação da pesquisa. Um dos poucos idosos que conseguiram assinar seu próprio nome completo.

Análogo ao rio que ali corre, a educação ribeirinha também já passou por vazantes $^{(\mathrm{m})}$. Tempos em que "o mais sábio da comunidade ensinava até onde se esgotava o conhecimento e cessava o que a comunidade aprendia"; tempos em que o cartilhão(n) era o simbolismo maior dos privilegiados que podiam ter acesso ao ensino nos dias em que a mão não se ocupava com a terra dos mais velhos. No decurso de ligeiros diálogos com os idosos e sensíveis trejeitos do assinar com o dedo, percebemos uma narrativa esperançosa. Parece mesmo que é tempo de subida dessas águas! Filhos e, sobretudo, netos já acessam com maior facilidade o ensino e a educação formal. É claro que ainda não alcançam níveis de cheias, mas a esperança que essas terras sejam inundadas pela educação infantil e de jovens e adultos é o que não falta a eles. 
CRIAÇÃO

"A pessoa que tá com a idade grande né, pelo uma parte precisa de companhia"

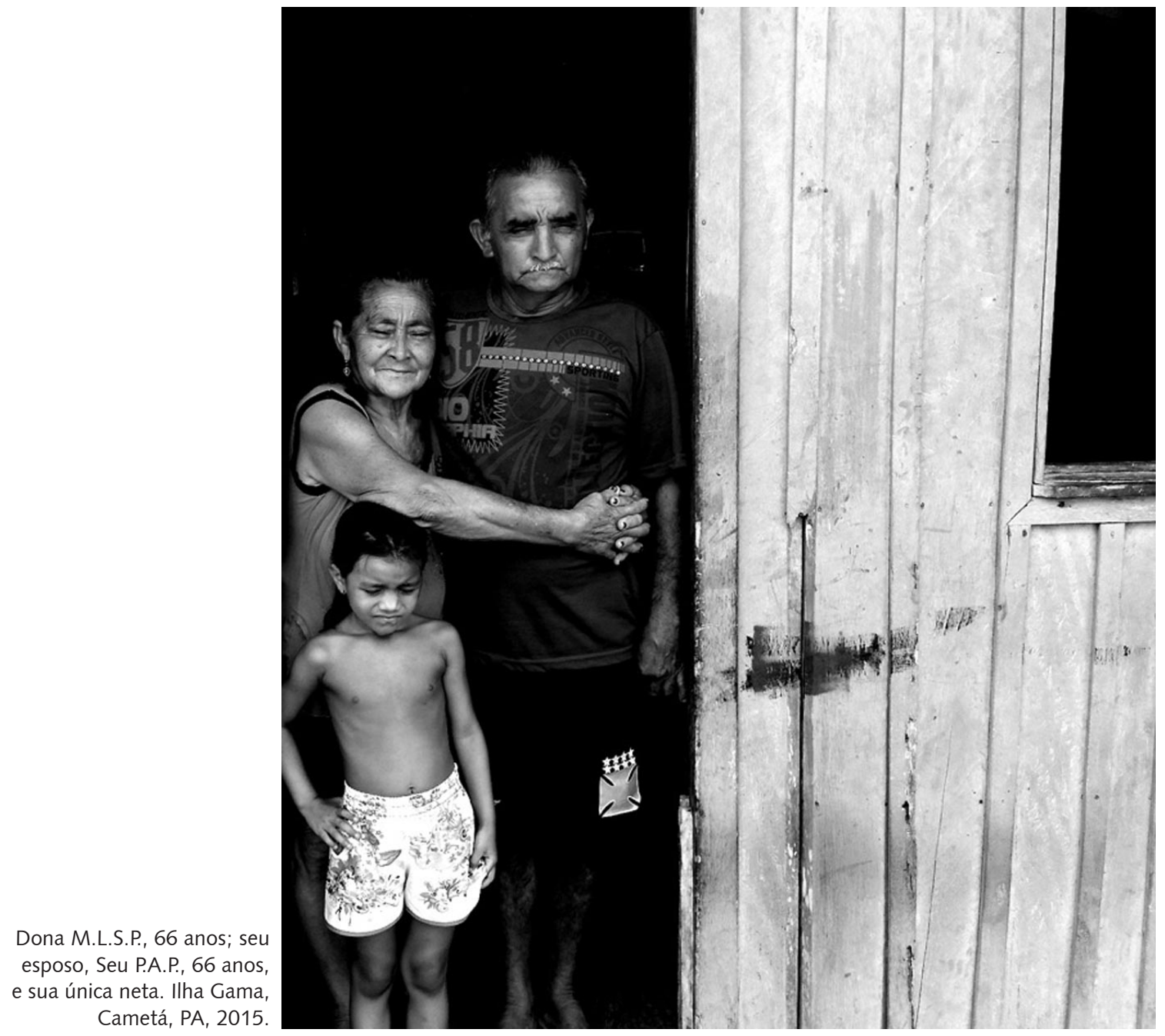

Um dia fui pequena, virei moça e fui crescendo pra vida aproveitar

Hoje já com a idade grande, não tenho escolha, sigo a amadurar

Vivo aqui com a saudade dos meus filhos que a cidade foram conquistar Trocaram a peconha ${ }^{(0)}$ por farda e maquiagem e não querem mais "vortar"

Nasci na beira do rio, pra aquelas bandas nunca quis morar Preferi ficar aqui e do marido, netos e sirinbabos ${ }^{(p)}$ cuidar

Na minha casa junto a família toda pros $\operatorname{causos}^{(9)}$ contar Graças a Deus tenho eles comigo, e é onde posso me apoiar. 

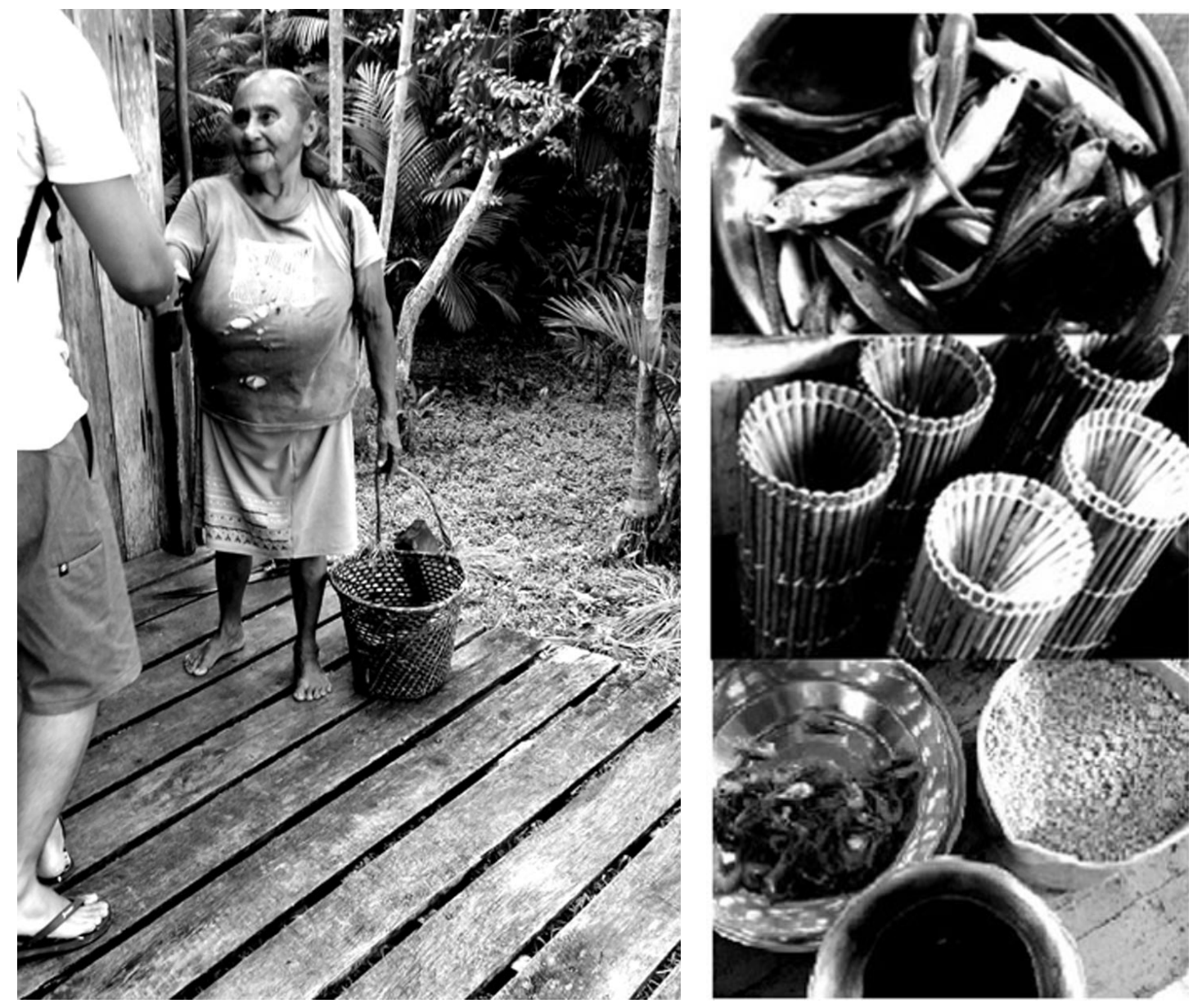

Em primeiro plano, Dona A.P.S., 75 anos. Ilha Mutuacazinho, Cametá, PA, no momento da chegada após coleta de açaí, cumprimentando um dos pesquisadores. Em sequência à direita, pescados e alguns matapis ${ }^{(r)}$. Por último, o que vai à

mesa do idoso ribeirinho, camarão seco, farinha de mandioca e açaí. Cametá, PA, 2015.

Minha senhora vai raiar o dia

Pula da rede e te joga água fria,

Que hoje só tem a garantia da farinha,

De umas duas tainha ${ }^{(s)}$ e o matapi pra tirar.

Meu facão já tá limado, limpo e afiado

Pro açaí da várzea arrastar.

Se a colheita ter resultado

Nós "vorta" do roçado

Com uns três paneiros do lado

Pra barriga alimentar. 
"É na buca da nute(t) que ato minha rede pra descansar"

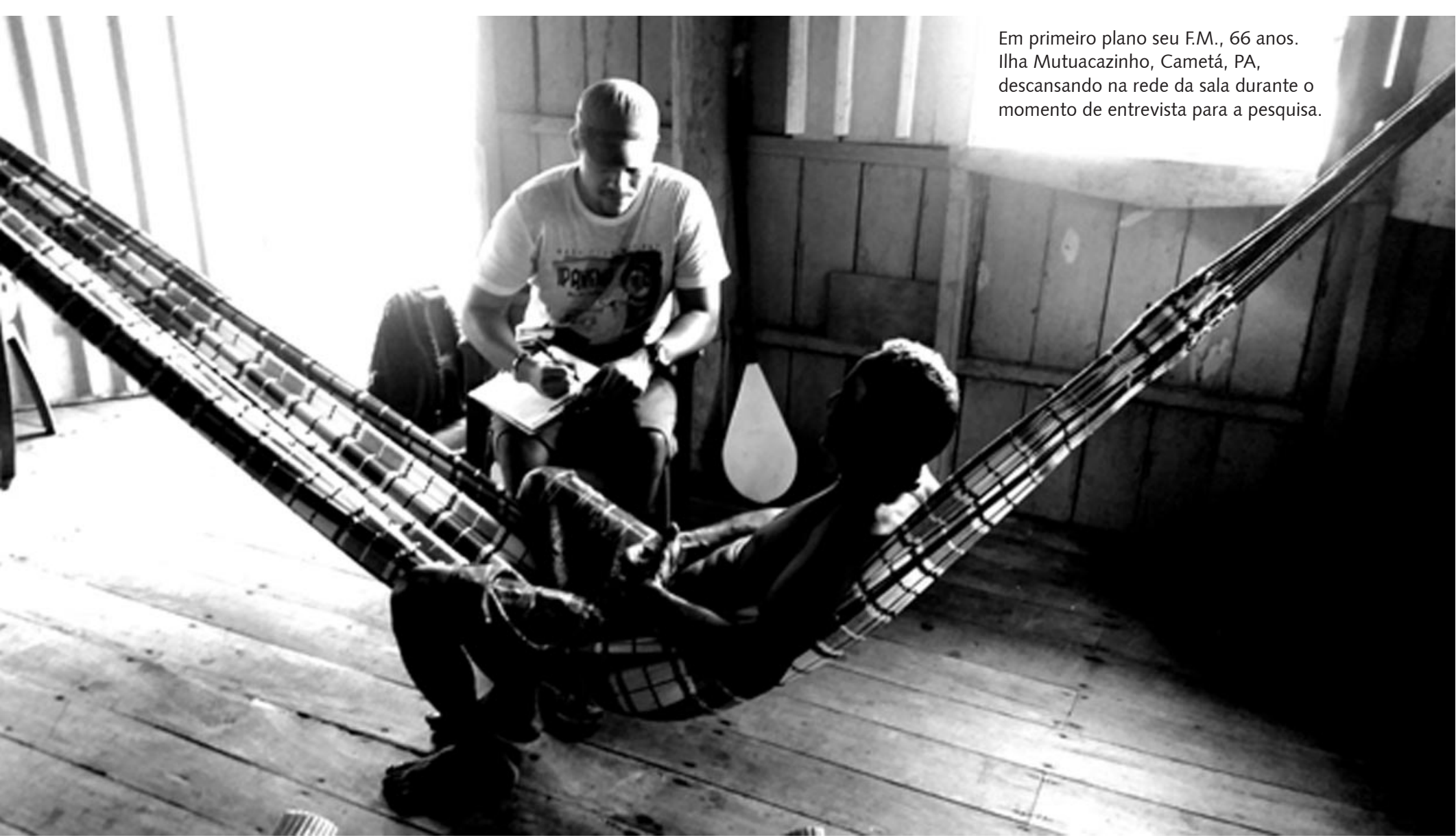




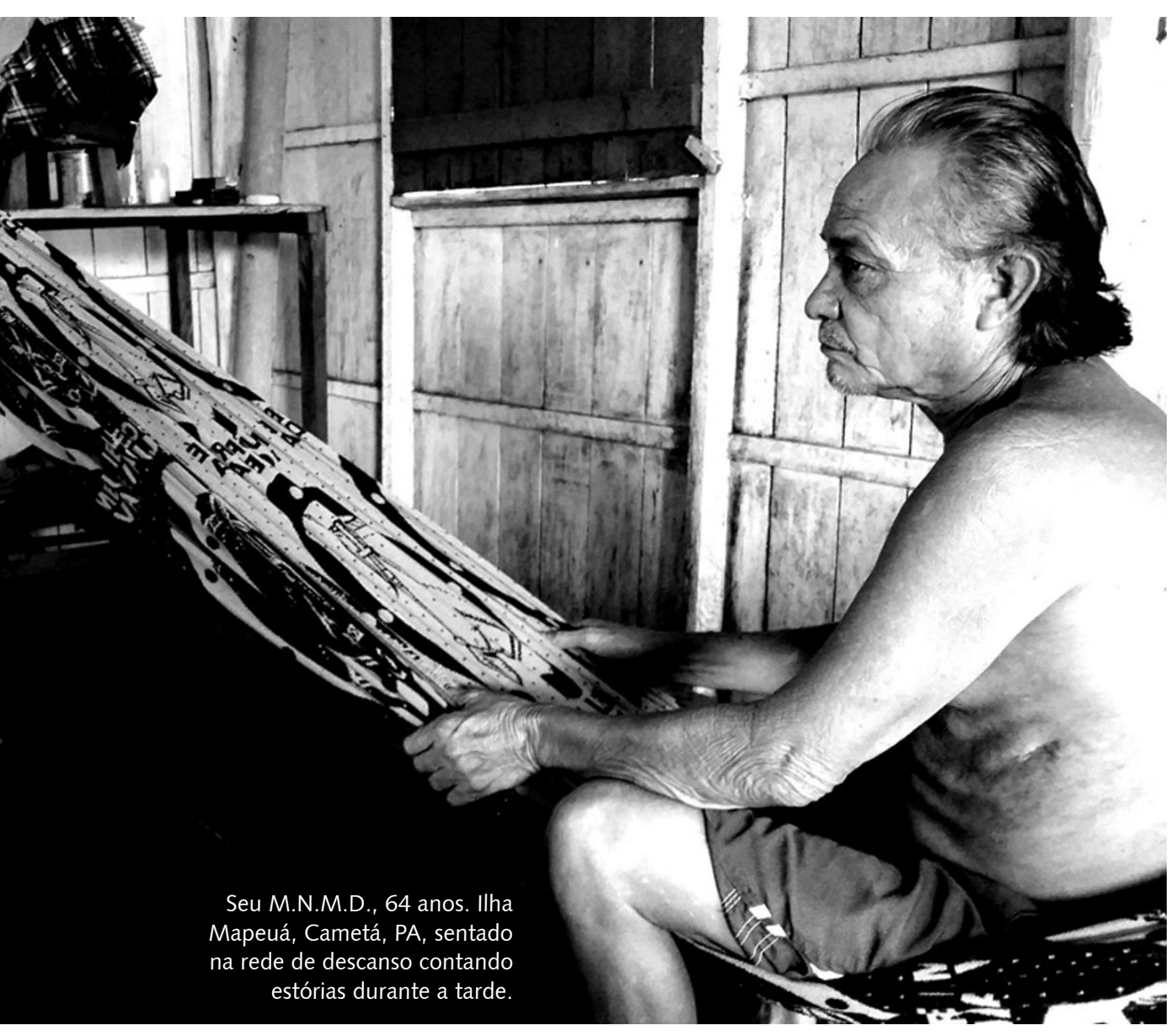

Enraizado e vindo de uma realidade indígena, moldar o corpo numa rede espraiou-se nas comunidades ribeirinhas amazônicas. Nos lares, embala desde as brincadeiras das crianças até o descansar do velho corpo. Após o almoço é atar e tirar o cochilo sagrado. Após a novela da noite é parar o motor, desenrolar e deleitar-se. Hábito recorrente e enaltecido culturalmente, sem sombras de dúvidas, foi o que mais marcou a identidade desses idosos em nossas visitas. É palavra de ordem, seja atracada em ganchos, nos esteios ou suspensa cortando a sala. Pode até passar despercebida aos olhos comuns, porém, é tecido resistente que acomoda no seu fundo um complexo câmbio de valores, de gostos e costumes. Na maturidade, é método de descanso e ócio em meio a balanços intermitentes e prazerosos, até que o tempo leve. 


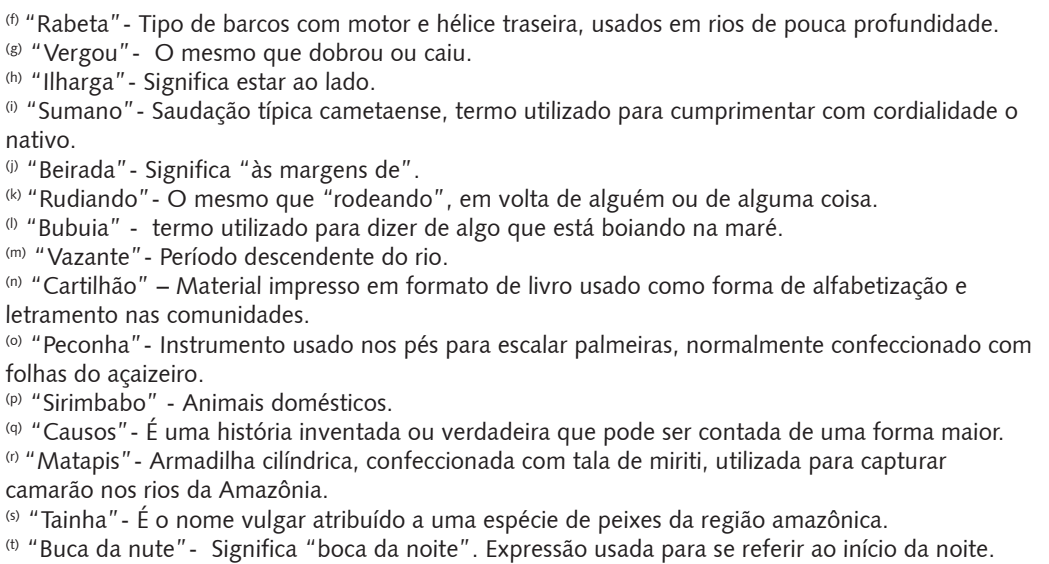

\section{Colaboradores}

O projeto e a idealização do manuscrito foram de responsabilidade do autor Rodolfo Gomes do Nascimento, junto ao autor Ronald de Oliveira Cardoso. Ambos trabalharam, igualmente, na construção do manuscrito e foram responsáveis pelos textos e pela composição do corpo de fotografias. As autoras Zeneide Nazaré Lima dos Santos, Denise da Silva Pinto e Celina Maria Colino Magalhães participaram da redação, revisão e edição final dos textos.

Esta produção tem o intuito de apresentar fotografias e textos, resultados de uma proposta de investigação sobre o ambiente e o cotidiano de idosos ribeirinhos amazônicos. Traz, na sua composição, elementos culturais típicos dessa região e peculiaridades próprias do processo de envelhecimento à margem dos rios.

Palavras-chave: Idoso. Ribeirinho. Amazônia. Cotidiano. Dialeto.

\section{The lifestyle of Amazon's riverine elderly in images and cultural language}

This production has the intent to present photos and texts, results of a research proposal about the environment and the daily life of Amazon's riverine elderly. Brings in its composition cultural elements typical of this region and own peculiarities of the aging process on the rivers' margin.

Keywords: Aged. Riverine. Amazon. Daily life. Dialect.

\section{La vida cotidiana de los ancianos de la Amazonia ribereña en imáenes y lenguaje cultural}

Su producción se destina para mostrar las fotos y textos, los resultados de un proyecto de investigación sobre el medio ambiente y la vida cotidiana de los ancianos de la Amazonia ribereña. Trae en su composición elementos culturales típicas de esta región y las particularidades del proceso de envejecimiento en los márgenes de los ríos.

Palabras clave: Ancianos. Ribereña. Amazonía. Cotidiano. Dialecto. 